\title{
ANÁLISE DE SUSTENTABILIDADE EM ASSENTAMENTO DE REFORMA AGRÁRIA: O CASO DE CHICO MENDES III, PERNAMBUCO, BRASIL ${ }^{1}$
}

\author{
Guillermo Gamarra-Rojas ${ }^{2}$ \\ Jorge Luiz Schirmer de Mattos ${ }^{3}$ \\ Cíntia Ferreira Lima Gamarra-Rojas ${ }^{4}$ \\ Patrícia Verônica Pinheiro Sales Lima ${ }^{5}$ \\ Francisco Roberto Caporal ${ }^{6}$
}

\begin{abstract}
RESUMO
No Assentamento Chico Mendes III, localizado na Zona da Mata, com sede no distrito de Tiúma, município de São Lourenço da Mata, estado de Pernambuco, Brasil, as famílias assentadas vêm vivenciando um processo de transição agroecológica e pesquisa-ação. Considerando que ainda se sabe pouco sobre a sustentabilidade dos agroecossistemas em assentamentos rurais, o estudo, realizado em 2011, se propôs a mensurar a sustentabilidade desse assentamento a partir da construção de um índice agregado, composto por um sistema de indicadores distribuídos em três atributos sistêmicos: produtividade, estabilidade e autogestão. Os resultados apontam que a redistribuição da terra, aliada a processos organizativos endógenos, juntamente com a revalorização de práticas agrícolas camponesas e a inovação agroecológica constituem elementos primários de um processo mais amplo de recampesinização no seio da reforma agrária. A metodologia utilizada mostrou-se válida e proporciona uma linha de base que pode ser utilizada em futura avaliação comparativa.
\end{abstract}

Palavras-chave: Agricultura camponesa, Agroecologia, atributos sistêmicos, indicadores de sustentabilidade.

\section{SUSTAINABILITY ANALYSIS IN AN AGRARIAN REFORM SETTLEMENT: THE CASE OF CHICO MENDES III, PERNAMBUCO, BRAZIL}

\footnotetext{
${ }^{1}$ FACEPE; MCT/CNPq

2 Graduado em Agronomia (UFAL). Mestrado em Ciências Agrárias (EAUFBA). Doutorado em Botânica (UFRPE). Professor do Departamento de Economia Agrícola e do Programa de Pós-Graduação em Economia Rural (UFC). E-mail: ggamarra@terra.com.br

3 Graduado em Agronomia (UPF). Mestrado em Zootecnia (UFLA). Doutorado em Zootecnia (UFV). Professor do Departamento de Educação (UFRPE). E-mail: js-mattos@hotmail.com

4 Graduada em Agronomia (EAUFBA). Mestrado em Ciências Agrárias (EAUFBA). E-mail: cintia.gamarra@gmail.com

${ }^{5}$ Graduada em Agronomia (UFC). Mestrado em Economia Rural (UFC). Doutorado em Economia Aplicada (USP). Professora do Departamento de Economia Agrícola e do Programa de Pós-Graduação em Desenvolvimento e Meio Ambiente (UFC). E-mail: pvpslima@gmail.com

${ }^{6}$ Graduado em Agronomia (UFSM). Mestrado em Extensão Rural (UFSM). Doutorado em Agroecología Campesinado e Historia (ISEC, Universidad de Córdoba, Espanha). Professor do Departamento de Educação (UFRPE). E-mail: caporalfr@gmail.com
} 


\begin{abstract}
In the Chico Mendes III settlement, located in the Zona da Mata, Tiúma district, state of Pernambuco, Brazil, settled families have been experiencing a process of agroecological transition and action research. Considering that knowledge about the sustainability of agroecosystems in rural settlements is still scanty, the study, carried out in 2011, aimed to measure the sustainability of this settlement based on the construction of an aggregate index composed of a system of indicators distributed in three systemic attributes: productivity, stability and self-management. The results suggest that land redistribution, coupled with endogenous organizational processes, alongside with the revaluation of peasant agricultural practices and agroecological innovation are the primary elements of a broader process of bringing back the peasantry within agrarian reform. The methodology proved to be valid and provides a baseline which can be used in further comparative evaluation.
\end{abstract}

Keywords: Agroecology, peasant agriculture, system attributes, sustainability indicators.

\title{
1. INTRODUÇÃO
}

Os assentamentos rurais constituem uma oportunidade de acesso à terra e alternativa de trabalho para uma população tradicionalmente excluída (LEITE et al., 2004). Representam a possibilidade de os assentados centrarem suas estratégias de reprodução familiar e de subsistência no próprio lote e, complementarmente, lançar mão de outras fontes de renda e de trabalho fora do lote. A presença dos assentamentos e das políticas públicas a eles associadas também atua como fator gerador de postos de trabalho não agrícolas e como dinamizador do comércio local nos municípios onde são implantados (LEITE et al., 2004).

O sujeito assentado é para muitos uma figura difusa devido à sua heterogeneidade. São pessoas oriundas do campo e da cidade com ocupações as mais diversas, marginalizadas dos frutos do desenvolvimento, que conseguiram organizar-se em torno da luta pela terra e direitos, a qual toma materialidade no assentamento rural. Ploeg (2008) argumenta que nas sociedades modernas esses milhões de pessoas que lutam por escapar da miséria rural e urbana, tornam-se eles mesmos camponeses, sendo que no Brasil o Movimento dos Trabalhadores sem Terra (MST) é o mais expressivo dessa tendência. O MST promove uma formação ampla das pessoas mobilizadas que, entre outros aspectos, procura forjar e afirmar uma identidade camponesa. Para o MST, o principal símbolo dessa identidade é o da "comunidade", na qual prevaleceriam a solidariedade interpessoal e os valores humanitários (CALVO-GONZÁLES, 2010). Ou seja, são pessoas que retomam ou adquirem a condição de camponês, seus valores e suas práticas, num processo de recampesinização. Para Ploeg (2008, p.23) a recampesinização é uma expressão moderna para a "luta por autonomia e sobrevivência em um contexto de privação e dependência".

Condizente com a sua dinâmica camponesa, o MST também vem refletindo e mudando a sua forma de produzir. Inicialmente foi influenciado pelos agentes do crédito para uma concepção produtivista que resultou em elevado endividamento para compra de insumos e tecnologia. Atualmente, vem orientando a adoção da Agroecologia como paradigma para a produção agropecuária em assentamentos (De'CARLI, 2013). Esse autor aponta a existência de duas dinâmicas que podem explicar a adoção da agroecologia pelo movimento: as parcerias com outras organizações da sociedade civil brasileira e latino-americana, como a Federação dos 
Estudantes de Agronomia do Brasil (FEAB), a Comissão Pastoral da Terra (CPT) e a Via Campesina; e as avaliações internas sobre as expectativas da produção dos assentamentos.

No nordeste brasileiro, muitos assentamentos rurais guardam a particularidade de terem sido criados dentro de engenhos falidos ou ociosos e improdutivos, nos quais os trabalhadores da cana-de-açúcar buscavam redefinir seus projetos de vida (NUNES DA SILVA et al., 2009). Esse é o caso do Assentamento Chico Mendes III, implantado em área do antigo engenho São João, cujas famílias assentadas vêm redesenhando seus agroecossistemas em bases mais sustentáveis via processo de transição agroecológica (MATTOS et al., 2017a). Isso mudou o modo de planejar, produzir e comercializar dos assentados, que começaram a desenvolver suas atividades produtivas de curto e médio prazos para atender à demanda por produtos com maior regularidade, quantidade e qualidade em bases mais sustentáveis (MATTOS et al., 2014).

Embora seja bem aceito que sistemas conduzidos segundo os princípios da Agroecologia tendem a ser mais sustentáveis (ASTIER, 2006), sabe-se pouco sobre os mecanismos que conferem uma maior ou menor sustentabilidade aos agroecossistemas em assentamentos rurais.

A ideia de sustentabilidade provém de um processo histórico de avaliação crítica da relação sociedade-natureza, que teve como resultado inúmeras definições para o conceito (BELLEN, 2005) e pode ser entendida como uma propriedade emergente do sistema socioambiental. Um produto de tomada de decisão coletiva resultante da interação dos diferentes sujeitos que compartilham determinado espaço geográfico e que são simultaneamente usuários e gestores dos recursos naturais (RÖLING; WAGEMAKERS, 1998). Esse enfoque pressupõe que os diversos sujeitos de alguma maneira se enxergam como componentes de um sistema e dependem e/ou influenciam o mesmo. Contudo, é nesta arena que se manifestam as contradições do padrão de desenvolvimento rural sustentável, as disputas de classe e as ideológicas. O quadro torna-se mais complexo quando se consideram, de forma combinada, os cenários atuais e futuros do crescimento populacional, das mudanças nos padrões alimentares, da insegurança energética e das mudanças climáticas (PRETTY et al., 2010).

Em relação à agricultura, existe uma série de atributos que os sistemas agrícolas devem apresentar para que sejam considerados sustentáveis (KOOHAFKAN et al., 2012). Tais atributos convergem para a adoção de comportamentos associados ao uso eficiente e consciente dos recursos, que respeitem processos agroecológicos e se preocupem com a conservação do solo, da água, da biodiversidade. Desta forma, a noção de sustentabilidade representa uma insatisfação com o padrão da agricultura moderna e a busca por "um modelo produtivo que garanta, por um lado, a segurança alimentar e, por outro lado, a conservação ecológica" (PIRES, 1996).

Como consequência, tem havido renovado interesse em estudos que buscam compreender e avaliar sistemas camponeses ou alternativos à modernização agrícola seja entre aqueles com maior poder de decisão na elaboração de políticas públicas e de estratégias de desenvolvimento rural, seja pelos que assessoram os agricultores ou os próprios sujeitos da ação (BACHEV; TREZIEV, 2018; HANNAA et al., 2016; RAMÍREZ-CARRILLO et al., 2018; OELBERMANN, 2014). Contudo, persiste uma abordagem focada na modernização agrícola, centrada em poucas variáveis, não dando conta da diversidade de agriculturas e de agricultores presentes no meio rural (GAMARRA-ROJAS; SILVA; VIDAL, 2017). 
Então, o desenvolvimento de referenciais conceituais e de marcos operacionais para compreender e avaliar a sustentabilidade continua sendo um importante desafio. Na perspectiva da agroecologia, trata-se de examinar a interface entre o sistema social e o agroecossistema. Este pode ser compreendido como "um sistema aberto e funcional de relações complementares entre organismos vivos e seu ambiente, delimitado por fronteiras escolhidas de forma mais ou menos arbitrária, as quais no tempo e no espaço parecem manter equilíbrio dinâmico" (GLIESSMAN, 2002).

Nos agroecossistemas o homem é um componente ativo que organiza e gerencia o sistema, podendo também estar envolvidos fatores externos às unidades de produção, que influenciam ou mesmo determinam a sua dinâmica, como os setores de apoio técnico ou de crédito, o mercado, as indústrias de insumos e transformação (ALTIERI; YURJEVIC, 1991). Woodhill e Röling (1998) argumentam que, sob a perspectiva cognitivo-construtivista, é preciso considerar as inter-relações entre diferentes dimensões, tais como: as práticas agrícolas, organizativas, de mercado etc.; o aprendizado dessas práticas; a mediação desse aprendizado; as estruturas e as redes institucionais (assessoria, pesquisa, mercados, etc.); as estruturas e as redes das políticas públicas; e a gestão da mudança do convencional para o sustentável.

Face à complexidade dos agroecossistemas, Conway (1986) sugeriu que a sustentabilidade, em termos dos seus efeitos dinâmicos, pode ser compreendida a partir de propriedades do sistema que, em conjunto, descrevem o essencial do comportamento dos agroecossistemas. Produtividade, equidade, estabilidade, resiliência, confiabilidade, adaptabilidade e autogestão são atributos sistêmicos que vêm sendo utilizados para tornar operativos os princípios gerais da sustentabilidade na agricultura (CONWAY, 1986; 1987; MARTEN, 1988; MASERA et al., 2000; HOLLING, 2001; LIMA; GAMARRA-ROJAS, 2017).

Por sua vez, os procedimentos específicos utilizados em estudos de sustentabilidade de agroecossistemas são diversos. Neste sentido, índices agregados podem ser uma ferramenta útil, pois permitem captar as multidimensões de um conceito (GBETIBOUO et al., 2010; TONMOY; EL-ZEIN, 2013) e gerar informações antes pouco perceptíveis. A construção de indicadores de sustentabilidade agrícola permite uma visão ampla do desenvolvimento uma vez que os mesmos podem integrar aspectos econômicos, sociais, políticos, culturais, institucionais e ambientais (GÓMEZ-LIMÓN; SANCHEZ-FERNANDEZ, 2010).

As principais funções dos indicadores são: avaliar situações e tendências, comparar localidades e situações, avaliar a situação e as tendências em relação aos objetivos e metas, fornecer informações antecipadas de alerta e prever condições e tendências futuras (CASTOLDI; BECHINI, 2010). Pode-se dizer, então, que um índice agregado de sustentabilidade constitui uma medida do desempenho global de um sistema, combinando dados sobre as características individuais e componentes do sistema. Trata-se de uma definição operacional do conceito, a qual permite uma quantificação necessária para a elaboração e monitoramento de políticas agrícolas em âmbito global ou local (SRINIVASA RAO et al., 2019).

Nesse cenário temático o estudo se propôs a mensurar a sustentabilidade do assentamento Chico Mendes III a partir da construção de um índice agregado, composto por um sistema de indicadores distribuídos em três atributos sistêmicos: produtividade, estabilidade e autogestão, com 0 intuito de contribuir para 0 diagnóstico de possíveis entraves que possam ser superados para a promoção da sustentabilidade no assentamento. 


\section{METODOLOGIA}

\subsection{O LOCAL DO ESTUDO E OS SUJEITOS DA PESQUISA}

O Assentamento Chico Mendes III, antigo Engenho São João, que resultou da luta do Movimento dos Trabalhadores Sem Terra (MST) desde 2004, localiza-se na Zona da Mata, a $3 \mathrm{~km}$ do distrito de Tiúma e a $7 \mathrm{~km}$ da cidade de São Lourenço da Mata, Pernambuco, Brasil. São 55 famílias assentadas numa área de 430 ha, que inclui a vila, a reserva legal e parcelas com área media de 5,5ha.

Até 2011, época de realização deste estudo, os assentados destacavam quatro marcos de referência na formação do assentamento. A fase de mobilização se deu no inicio de 2004 com o trabalho de base do MST, para agregar militantes, o qual contou com o apoio de simpatizantes do movimento. O trabalho de base é organizado pelo MST em grupos setoriais, quais sejam: formação, educação, cultura, saúde, produção, disciplina e frente de massa (GAMARRA-ROJAS; MATTOS, 2013).

A quebra da porteira do engenho São João, realizada por cerca de 1640 pessoas, em março de 2004, inicia a fase de acampamentos e constitui o primeiro encontro do/as atuais assentado/as. Até o início de 2006 cerca de 250 pessoas mobilizadas montaram acampamento em Pau D’Alho, posteriormente no Colégio Agrícola Dom Agostinho Ikas em São Lourenço da Mata e às margens da rodovia que passa ao lado do atual assentamento (GAMARRA-ROJAS; MATTOS, 2013).

Em março de 2006 houve a segunda Quebra de Porteira com cerca de 300 pessoas, dando inicio à fase de organização. Foram decididos os critérios de escolha dos assentados em assembleia, resultando na seleção de 55 famílias, que passaram a constituir a Relação de Beneficiários (RB) do INCRA. Em 12 de outubro de 2008 se deu a emissão de posse pelo INCRA, quando o Assentamento passou a ser denominado de Chico Mendes III. Até 2008 os assentados desenvolveram duas atividades básicas sob a orientação do MST: a militância, para apoiar as bandeiras e dar visibilidade aos acampamentos do MST e a produção agrícola coletiva (GAMARRA-ROJAS; MATTOS, 2013).

A fase de conquistas e esperanças compreende o período de finais de 2008 a 2011, onde se destacam: uma tentativa de construção do Plano de Desenvolvimento do Assentamento (PDA); a chegada da equipe de pesquisa-ação da UFRPE; a criação da associação de Chico Mendes III; a consolidação da escola de alfabetização de jovens e adultos do assentamento em parceria com a prefeitura de São Lourenço da Mata. Contudo, também ocorreu a invasão de 144 ha da área do Assentamento por um homem de poder da região. Essa área foi re-ocupada pelos assentados em 11 de outubro de 2009. Depois da emissão de posse a direção do movimento dividiu e sorteou lotes na beira do rio para a implantação de cultivos irrigados (GAMARRA-ROJAS; MATTOS, 2013).

As famílias assentadas são oriundas da zona da mata e do agreste de Pernambuco, sem vínculo anterior com o Engenho, mas sim com a cana-de-açúcar. Em sua maioria consideram-se negros $(61 \%)$ e outros morenos $(19 \%)$, pardos $(10 \%)$ e brancos ou mestiços (10\%). A idade já era bastante avançada, variando de 30 a 72 anos, com media de 54 anos. As famílias são numerosas, com até 19 filhos e media de seis filhos por família. Entretanto, em sua maioria somente o(a) titular e cônjuge residem no assentamento. O nível de escolaridade é baixo, pois $29 \%$ não tem escolaridade, $10 \%$ são alfabetizados, $49 \%$ tem $1^{\circ}$ grau completo, $8 \%$ o $2^{\circ}$ grau completo e $4 \%$ cursaram superior completo. 
A composição da renda familiar provém de benéficos sociais, da produção agropecuária no assentamento, da transformação de produtos vegetais e de atividades não agrícolas. Dos benefícios sociais destacam-se a cesta básica proporcionada pelo INCRA (67\%) e a aposentadoria (30\%). Na produção agropecuária participam $92 \%$ dos entrevistados e/ou respectivo cônjuge, $22 \%$ tem a participação dos filhos e $35 \%$ contratam trabalhadores temporários. Os produtos transformados se baseiam principalmente na mandioca e são direcionados ao consumo familiar. As atividades não agrícolas são restritas à construção civil (10\%).

Os assentados destacam o MST na organização, formação politica e principalmente no acesso à terra $(90 \%)$ e a UFRPE no papel de assessoria técnica e produção de conhecimento agroecológico (50\%).

A profissão/ocupação e as relações com organizações sociais revela a existência de vivência rural dos assentados anterior ao assentamento, pois $80 \%$ declararam ter sido agricultores autônomos ou trabalhadores na agricultura, outros $20 \%$ praticaram diversidade de serviços urbanos e rurais. As formas de acesso à terra se deram como morador $(70 \%)$, arrendatário ou foreiro $(30 \%)$. As relações prévias com organizações incluíam a igreja (59\%), o sindicato rural (36\%), associações (16\%) e o MST (12\%).

Como consequência, o assentamento tem uma estrutura organizacional baseada no MST, com cinco núcleos de famílias compostas por 11 famílias cada. Com a criação da associação foram ampliadas as opções na busca de atendimento aos seus direitos para consolidação do assentamento. Essas instâncias organizativas seguem seus próprios regimentos e os assentados participam das mesmas indistintamente (GAMARRA-ROJAS; MATTOS, 2013). As mulheres têm se destacado como lideranças na associação e junto ao MST e, ainda, a titularidade dos lotes recai nas mulheres do assentamento em $80 \%$ das famílias, mesmo com a existência de cônjuge.

\subsection{A PESQUISA-AÇÃO EM CHICO MENDES III}

Desde 2009, um grupo de assentados e uma equipe de pesquisa e extensão em agroecologia da UFRPE, composto por professores, pesquisadores e estudantes dos Cursos de Agronomia e de Licenciatura em Ciências Agrárias da UFRPE e técnicos-agricultores externos, denominados de formadores, detentores de conhecimento prático da agricultura de base agroecológica e experimentados na metodologia Camponês a Camponês (MATTOS et al., 2017b), vêm se empenhando num projeto de desenvolvimento do Assentamento pautado em Agroecologia como ciência para orientar a coevolução de grupos sociais e sistemas convencionais de produção a sistemas socioambientais diversificados, mais autossuficientes e com maior capacidade de autodeterminação (GAMARRA-ROJAS; MATTOS, 2013). Contou com o apoio de financiamentos obtidos de programas de fomento à pesquisa e extensão (Quadro 1). 
Quadro 1 - Projetos para a transição agroecológica em Chico Mendes III, PE.

\begin{tabular}{|c|c|c|}
\hline Projeto & Fonte & Ano \\
\hline $\begin{array}{l}\text { Transição agroecológica no } \\
\text { Assentamento Chico Mendes-PE }\end{array}$ & $\begin{array}{l}\text { Edital MCT/CNPq Universal - Faixa A - } \\
\text { 15.2007, Processo: 486184-2007.2 }\end{array}$ & $\begin{array}{l}2008 \\
2010\end{array}$ \\
\hline $\begin{array}{l}\text { Camponês a Camponês: uma } \\
\text { metodologia para a Transição } \\
\text { Agroecológica no Assentamento Chico } \\
\text { Mendes-PE }\end{array}$ & $\begin{array}{l}\text { Edital } 33 \mathrm{MCT} / \mathrm{CNPq} / \mathrm{MDA} / \mathrm{SAF} / \mathrm{DATER} \text {, } \\
\text { Processo: } 558743 / 2009-9\end{array}$ & $\begin{array}{l}2010 \\
2011\end{array}$ \\
\hline \multirow{2}{*}{$\begin{array}{l}\text { Monitoramento da Transição } \\
\text { Agroecológica no Assentamento Chico } \\
\text { Mendes III - PE }\end{array}$} & $\begin{array}{l}\text { FACEPE. Bolsa de Fixação de } \\
\text { Pesquisador. Processo: № BFP-0001- } \\
5.01 / 10\end{array}$ & $\begin{array}{l}2010 \\
2011\end{array}$ \\
\hline & $\begin{array}{l}\text { Edital MCT/CNPq 14/2010 - Universal - } \\
\text { Faixa A, Processo: } 484275 / 2010-0\end{array}$ & $\begin{array}{l}2010 \\
2011\end{array}$ \\
\hline $\begin{array}{l}\text { Transição Agroecológica no } \\
\text { Assentamento Chico Mendes III: } \\
\text { educação ambiental e revegetação das } \\
\text { margens dos rios Goitá e Tapacurá }\end{array}$ & $\begin{array}{l}\text { PROEXT 2010 - SIG Proj No: } \\
49145.308 .6012 .15052010\end{array}$ & $\begin{array}{l}2011 \\
2011\end{array}$ \\
\hline
\end{tabular}

Fonte: Elaboração própria

As estratégias e metodologias dessa extensão agroecológica foram pautadas na pesquisa-ação e na metodologia camponês-a-camponês e incluem reuniões semanais, mutirões, oficinas, vistas de intercâmbio e práticas nos agroecossistemas. Iniciou-se com um diagnóstico rural participativo, visitas a agricultores e feiras agroecológicas e com uma unidade de referência agroecológica coletiva, cuja finalidade primeira foi a de estabelecer espaços pedagógicos (MATTOS et al., 2017b). Essa unidade deu origem ao nome do grupo: 'roçado de estudo', que em 2011 representava 50\% das famílias assentadas, com presença majoritária de mulheres. Após a delimitação dos lotes familiares o grupo foi estimulado à produção de hortaliças em roçados agroecológicos individuais, irrigados durante o período de seca, à organização de espaços de comercialização para os produtos do assentamento (GAMARRA-ROJAS; MATTOS, 2013) e à gestão de bens comuns, como a preservação de nascentes e da vegetação ribeirinha.

Dessas interações resultou uma maior utilização de práticas sustentáveis nos roçados, a proscrição do uso de agrotóxicos e o controle da queimada por meio da aplicação de multas aos infratores (GAMARRA-ROJAS; MATTOS, 2013). A participação dos agricultores formadores provocou mudanças na dinâmica da construção e troca de conhecimento, devido à horizontalidade nas relações baseadas no diálogo, com a mesma linguagem dos assentados, o que contribuiu para 0 estabelecimento de uma relação de confiança entre formadores e aprendentes (MATTOS et al., 2017b). Assim, o roçado de estudo apresenta feições de uma comunidade de aprendizagem, que se reúne em torno da geração e gestão de conhecimento agroecológico e se articula às instâncias organizativas do assentamento. O principal resultado é a confiança, a UFRPE contribui a dar legitimidade ao assentamento perante a sociedade local, proporcionando aos assentados maior poder nas lutas pela consolidação e desenvolvimento do assentamento (GAMARRA-ROJAS; MATTOS, 2013).

O projeto Monitoramento da Transição Agroecológica (Quadro 1), do qual o presente estudo constitui um dos seus produtos, foi apresentado aos assentados em reuniões semanais do roçado de estudo em 2010, oportunidades em que foram discutidas e acordadas as linhas gerais da pesquisa e a forma de realização das entrevistas. 


\subsection{NATUREZA, AMOSTRAGEM E INSTRUMENTOS DA PESQUISA}

A pesquisa, de caráter descritivo, avaliativo e explicativo, se insere na categoria estudo de caso (YIN, 2005). Foi realizada entre dezembro de 2010 e fevereiro de 2011, tendo como referência o ano de 2010. Das famílias assentadas, 49 (89\%) participaram do estudo.

A coleta de informações foi realizada por meio de um questionário semiestruturado que deu origem a um banco de dados para viabilizar estudos analíticos e prospectivos sobre o assentamento. O roteiro foi elaborado com foco na família, com os seguintes conteúdos: características da família; saúde; educação; profissão/ofícios; bens móveis e imóveis; renda; meio ambiente; trabalho; cultivos; criações; práticas de manejo; beneficiamento e transformação; comercialização; assistência técnica e organização social.

As entrevistas tiveram como referência a Relação de Beneficiários (RB) do Projeto INCRA/SR (03): PE0382000 - PA CHICO MENDES III; Município de São Lourenço da Mata - PE, de 27.01.2009. Foi constituído um grupo de quatro entrevistadores, dentre os membros da equipe de pesquisa-ação da UFRPE, para realizar entrevistas individuais nas residências e durante caminhadas transversais nos lotes dos assentados, com duração de 60 a 90 min. As questões sendo respondidas pela(o) titular, com ou sem participação do(a) respectivo cônjuge.

\subsection{CÁLCULO DOS ÍNDICES DE PRODUTIVIDADE, ESTABILIDADE E AUTOGESTÃO}

Os atributos sistêmicos utilizados no presente estudo foram escolhidos a partir dos seguintes critérios: que se referissem às três dimensões de avaliação da sustentabilidade: ambiental, econômica e social; que houvesse no banco de dados informação suficiente para a realização de uma análise estatística.

Assim, dos sete atributos propostos por Masera, foram escolhidos três: produtividade, estabilidade e autogestão, que atendem aos critérios acima enunciados. Em sentido amplo, produtividade é a capacidade de um agroecossistema fornecer o nível necessário de bens e serviços (MASERA et al., 2000). Com o termo estabilidade esses autores se referem à propriedade do sistema de ter um estado de equilíbrio dinâmico. Implica em constância de produtividade em face de pequenos distúrbios que podem ocorrer normalmente ou em função dos ciclos ambientais (CONWAY, 1987). Neste sentido, o termo também pode ser interpretado como resistência. Já autonomia ou autogestão, em termos sociais, seria a capacidade do sistema regular e controlar em maior ou menor grau as suas interações com o exterior (MASERA et al., 2000).

Cada um dos atributos foi descrito por um conjunto de indicadores quantificados por meio da atribuição de escores expressos por meio de uma escala crescente, variando de uma situação insustentável (escore 0) a uma situação mais sustentável (escore 3).

Os indicadores componentes do atributo produtividade, Tabela 1, estão relacionados à diversidade de produtos dos agroecossistemas das famílias assentadas, no sentido de atender a um único propósito (consumo familiar ou venda) ou a ambos os propósitos (consumo familiar e venda). Considerou-se que a produção para consumo familiar e venda é mais sustentável em termos econômicos, pois permite atender à segurança alimentar (autoconsumo) e simultaneamente gerar renda para adquirir produtos ou serviços não disponíveis localmente. 
Tabela 1 - Indicadores de produtividade

\begin{tabular}{llc}
\hline \multicolumn{1}{c}{ Indicador } & \multicolumn{1}{c}{ Níveis/parâmetros } & Escores \\
\hline \multirow{3}{*}{$\begin{array}{ll}\text { Produção de animais de } \\
\text { pequeno porte }\end{array}$} & Não produz & 0 \\
& Produz para consumo familiar & 1 \\
& Produz para venda & 2 \\
& Produz para consumo familiar e venda & 3 \\
\hline \multirow{2}{*}{ Produção de animais de grande } & Não produz & 0 \\
porte & Produz para consumo familiar ou trabalho & 1 \\
& Produz para venda & 2 \\
& Produz para consumo familiar e venda & 3 \\
\hline \multirow{5}{*}{ Produção de hortaliças } & Não produz & 0 \\
& Produz para consumo familiar & 1 \\
& Produz para venda & 2 \\
Produção de cultivos de ciclo & Produz para consumo familiar e venda & 3 \\
\hline curto & Não produz & 0 \\
& Produz para consumo familiar & 1 \\
\hline & Produz para venda & 2 \\
\hline
\end{tabular}

Fonte: Elaboração própria

Os indicadores de estabilidade referem-se às práticas de produção agrícola nos agroecossistemas e ao uso dos bens comuns do assentamento (Tabela 2).

Tabela 2 - Indicadores de estabilidade

\begin{tabular}{llc}
\hline \multicolumn{1}{c}{ Indicador } & \multicolumn{1}{c}{ Níveis/parâmetros } & Escores \\
\hline $\begin{array}{lll}\text { Produção agrícola: maior diversidade } \\
\text { de espécies, maior possibilidade de }\end{array}$ & Não produz & Produz hortaliças \\
rendimentos e de alimentos, logo, & Produz cultivos de ciclo curto & 1 \\
menores riscos para a economia e & Produz hortaliças e cultivos de ciclo curto & 3 \\
alimentação. & Não cria animais & 0 \\
\hline & Cria animais de pequeno porte & 1 \\
Produção de animais: idem & Cria animais de grande porte & 2 \\
& Cria animais de pequeno e grande porte & 3 \\
\hline Boas práticas sustentáveis de & Não utiliza & 0 \\
manejo (cobertura morta, adubação & Utiliza uma prática & 1 \\
orgânica e policultivo): quanto mais & Utiliza duas práticas & 2 \\
práticas, maior a homeostase do & Utiliza três práticas & 3 \\
agroecossistema. & Não cultiva & 0 \\
\hline Preparo da terra: quanto maior o & Utiliza trator & 1 \\
revolvimento do solo associado & Preparo manual e com trator & 2 \\
trator, maior a possibilidade de & Preparo manual & 3 \\
degradação e maior a dependência & Não faz controle & 0 \\
financeira. & Controle químico & 1 \\
\hline Controle de pragas e doenças: & Controle químico e alternativo & 2 \\
quanto menor o uso de agrotóxicos & Controle alternativo & 3 \\
menor dependência financeira e & Para animais, atividades domésticas e & 0 \\
contaminação. & irrigação & 1 \\
\hline & Para animais & 2 \\
Usos das nascentes: quanto menor & 3 \\
utilização, maior a preservação e & Para atividades domésticas e irrigação & 0 \\
restauração ecológica. & Não utiliza & Para animais, atividades domésticas e \\
\hline Usos dos rios: idem & &
\end{tabular}




\begin{tabular}{lll}
\hline \multicolumn{1}{c}{ Indicador } & \multicolumn{1}{c}{ Níveis/parâmetros } & Escores \\
\hline & irrigação & \\
& Para animais & 1 \\
& Para atividades domésticas e/ou irrigação & 2 \\
& Não utiliza & 3 \\
\hline \multirow{4}{*}{ Usos da mata nativa: idem } & Retira lenha e madeira para construção & 0 \\
& Retira lenha & 1 \\
& Retira madeira para construção & 2 \\
& Não utiliza & 3 \\
\hline Destino do lixo domiciliar: quanto & Descarta & 0 \\
maior a exposição, maior a & Enterra & 1 \\
probabilidade de contaminações e & Enterra e/ou queima & 2 \\
menor aproveitamento do material & Recicla & 3 \\
orgânico & & \\
\hline Fon & &
\end{tabular}

Fonte: Elaboração própria

Os indicadores de autogestão compreendem dois grupos: um relacionado à autogestão social e o outro à autonomia produtiva do agroecossistema (Tabela 3).

Tabela 3 - Indicadores de autogestão

\begin{tabular}{|c|c|c|}
\hline Indicador & Níveis/parâmetros & Notas \\
\hline \multirow{4}{*}{$\begin{array}{l}\text { Participação em organizações antes } \\
\text { de assentado: a interação em torno } \\
\text { de motivações e objetivos comuns } \\
\text { promovem aprendizagens e o } \\
\text { desenvolvimento de competências } \\
\text { individuais e organizacionais, o que } \\
\text { facilita o melhor aproveitamento de } \\
\text { oportunidades e/ou a busca de } \\
\text { soluções para superar adversidades. }\end{array}$} & Nunca participou & 0 \\
\hline & Participou de organização religiosa & 1 \\
\hline & Participou de organização/movimento social & 2 \\
\hline & $\begin{array}{l}\text { Participou de organização religiosa e } \\
\text { movimento social }\end{array}$ & 3 \\
\hline \multirow{4}{*}{$\begin{array}{l}\text { Participação em organizações na } \\
\text { atualidade: idem }\end{array}$} & Nunca participou & 0 \\
\hline & Participou de organização religiosa & 1 \\
\hline & Participou de organização/movimento social & 2 \\
\hline & $\begin{array}{l}\text { Participou de organização religiosa e } \\
\text { movimento social }\end{array}$ & 3 \\
\hline \multirow{4}{*}{$\begin{array}{l}\text { Proveniência das sementes de } \\
\text { hortaliças: quanto maior a utilização } \\
\text { de recursos locais, menor a } \\
\text { dependência financeira. }\end{array}$} & Não cultiva hortaliças & 0 \\
\hline & Adquire sementes no comércio & 1 \\
\hline & $\begin{array}{l}\text { Utiliza sementes próprias e adquire no } \\
\text { comércio }\end{array}$ & 2 \\
\hline & Utiliza sementes próprias & 3 \\
\hline \multirow{4}{*}{$\begin{array}{l}\text { Proveniência das sementes de } \\
\text { cultivos de ciclo curto: idem }\end{array}$} & Não planta cultivos de ciclo curto & 0 \\
\hline & Adquire sementes no comércio & 1 \\
\hline & $\begin{array}{l}\text { Utiliza sementes próprias e adquire no } \\
\text { comércio }\end{array}$ & 2 \\
\hline & Utiliza sementes próprias & 3 \\
\hline \multirow{4}{*}{$\begin{array}{l}\text { Proveniência da alimentação dos } \\
\text { animais de pequeno porte: idem }\end{array}$} & Não cria animais de pequeno porte & 0 \\
\hline & Adquire o alimento no comércio & 1 \\
\hline & Utiliza alimento local e adquire no comércio & 2 \\
\hline & Utiliza alimento local & 3 \\
\hline \multirow{4}{*}{$\begin{array}{l}\text { Proveniência da alimentação dos } \\
\text { animais de grande porte: idem }\end{array}$} & Não cria animais de grande porte & 0 \\
\hline & Adquire o alimento no comércio & 1 \\
\hline & Utiliza alimento local e adquire no comércio & 2 \\
\hline & Utiliza alimento local & 3 \\
\hline
\end{tabular}

Fonte: Elaboração própria 
Antes de calcular o Índice de Sustentabilidade (IS) optou-se pela agregação de indicadores de cada atributo nos subíndices de Produtividade (IP), Estabilidade (IE) e Autogestão (IA). Matematicamente as equações do indicador, do sub-índice e do índice (Equações de 1 a 3) foram adaptadas de SOUZA et al (2017):

i) Indicadores componentes dos subíndices

$$
\text { Iiw }=\frac{1}{n} \sum_{j=1}^{n} \frac{1}{m} \frac{E_{i j}}{E \max _{i}}
$$

ii) Subíndices referentes a cada atributo

$$
I W=\sum_{i=1}^{m} I_{i w}
$$

iii) Índice de Sustentabilidade

$$
I S=\sum_{w=1}^{p} I W
$$

Onde:

IS = Índice de Sustentabilidade

IW = Subíndice referente ao atributo $\mathrm{w}$

liw $=$ Valor do Indicador $\mathrm{i}$, componente do atributo $\mathrm{w}$

$E i j$ = escore do i-ésimo indicador do atributo w obtido pelo j-ésimo agricultor;

$E$ max $i=$ escore máximo do i-ésimo indicador do atributo w;

$\mathrm{i}=1, \ldots, \mathrm{m}$, representa os indicadores do atributo $\mathrm{w}$;

$\mathrm{j}=1, \ldots, \mathrm{n}$, representa os agricultores.

$\mathrm{w}=1, \ldots, \mathrm{p}$ (representa os atributos produtividade, estabilidade ou autogestão)

Quanto mais próximo de 1, maior o nível de sustentabilidade. Tendo como base Barreto et al. (2005), optou-se por estabelecer o seguinte critério:
a) baixo nível de Sustentabilidade
$0<$ IS ou IW $\leq 0,5$
b) médio nível de Sustentabilidade
$0,5<$ IS ou IW $\leq 0,8$
c) alto nível de Sustentabilidade
$0,8<$ IS ou IW $\leq 1,0$

\section{RESULTADOS E DISCUSSÃO}

\subsection{PRODUTIVIDADE EM CHICO MENDES III}

$\mathrm{Na}$ composição do subíndice de Produtividade (IP) geral dos agroecossistemas familiares observa-se que o indicador Produção de cultivos de ciclo curto $(0,918)$ supera de forma expressiva a dos demais indicadores (Tabela 4). $\mathrm{O}$ fato de a grande maioria das famílias assentadas produzirem cultivos de ciclo curto - batata doce, feijão, inhame, jerimum e macaxeira - tanto para o consumo familiar quanto para venda, reflete o bom desempenho deste indicador na constituição do IP.

O cultivo dessas espécies se dá em diversas combinações espaciais e temporais. A sua ampla disseminação nos agroecossistemas do assentamento leva a considera-la como uma prática herdada da agricultura tradicional da Zona da Mata do Nordeste, a qual vem cumprindo a dupla função de, por um lado, garantir o 
autoconsumo e assim a segurança alimentar e nutricional das famílias assentadas e, por outro, gerar renda para adquirir bens não produzidos localmente. Para Toledo (1992) essa diversidade caracterizaria a principal estratégia da produção camponesa, porque a variedade (geográfica, de espécies, genética, etc.) constitui em si um mecanismo para reduzir o risco a que historicamente estão sujeitos esses agricultores.

Tabela 4. Participação dos indicadores nos Subíndices de Produtividade (IP), Estabilidade (IE) e Autogestão (IA) em Chico Mendes III, 2010.

\begin{tabular}{|c|c|c|}
\hline Indicadores & Valor Absoluto & Contribuição \\
\hline \multicolumn{3}{|c|}{ Subíndice de Produtividade (IP) } \\
\hline Produção de cultivos de ciclo curto & 0,918 & 47 \\
\hline Produção de hortaliças & 0,476 & 24 \\
\hline Produção de animais de grande porte & 0,327 & 17 \\
\hline Produção de animais de pequeno porte & 0,245 & 12 \\
\hline IP & 0,492 & 100 \\
\hline \multicolumn{3}{|l|}{ Índice de Estabilidade (IE) } \\
\hline Produção agrícola & 0,857 & 15 \\
\hline Boas práticas de manejo & 0,762 & 13 \\
\hline Usos dos rios & 0,755 & 13 \\
\hline Reciclagem do lixo & 0,735 & 13 \\
\hline Preparo da terra & 0,626 & 11 \\
\hline Produção de animais & 0,578 & 10 \\
\hline Usos das nascentes & 0,510 & 9 \\
\hline Uso da mata nativa & 0,463 & 8 \\
\hline Controle de pragas e doenças & 0,395 & 7 \\
\hline IE & 0,631 & 100 \\
\hline \multicolumn{3}{|l|}{ Índice de Autogestão (IA) } \\
\hline Participação em organizações na atualidade & 0,816 & 24 \\
\hline Proveniência das sementes de cultivos de ciclo curto & 0,667 & 20 \\
\hline Participação em organizações antes de assentado & 0,551 & 16 \\
\hline Proveniência da alimentação dos animais de grande porte & 0,531 & 16 \\
\hline Proveniência das sementes de hortaliças & 0,415 & 12 \\
\hline Proveniência da alimentação de animais de pequeno porte & 0,367 & 11 \\
\hline IA & 0,558 & 100 \\
\hline
\end{tabular}

Fonte: Dados da pesquisa.

No entanto, o valor do IP do assentamento apenas aproxima-se do nível médio de sustentabilidade $(0,492)$, o que se explica pelo fato de que das 49 famílias pesquisadas, somente oito (16\%) produziam cultivos de ciclo curto e hortaliças, bem como criavam pequenos e grandes animais em quantidade suficiente para atender ao consumo familiar e à venda.

Vale lembrar que à época do estudo fazia dois anos que os agricultores tinham sido assentados, as áreas dos lotes das famílias não estavam definidas, nem os recursos financeiros para aquisição de animais e instrumentos de trabalho tinham sido disponibilizados aos assentados pelo INCRA. Essa condição de indefinição de área física para se estabelecer e realizar uma produção permanente e a indisponibilidade temporária de recursos financeiros certamente influenciou o IP negativamente. Tanto é assim que sequer foi considerada a inclusão da variável 'produção de cultivos de ciclo longo', tais como frutíferas perenes, quando da definição dos indicadores que viriam a compor os indicadores do sub-índice de produtividade. Assim, é possível supor que atendidas essas condições, esse quadro passe a mudar. 
Nesse sentido, cabe destacar a potencial influência dos incentivos cognitivos e financeiros do Grupo de Pesquisa em Agroecologia da UFRPE à produção de hortaliças e à conformação de sistemas agroflorestais, iniciados à época. Essas ações, que buscam revitalizar e potencializar a capacidade produtiva dos agroecossistemas, poderão ter efeitos na diversidade de cultivos - tanto de ciclo curto quanto de ciclo longo - e de alimentos para consumo e venda nas feiras das quais os assentados fazem parte (MATTOS et al., 2017b) e influenciar positivamente a produtividade.

\subsection{ESTABILIDADE EM CHICO MENDES III}

O valor do Índice de Estabilidade (IE) geral é médio, uma vez que a maioria dos agricultores já vem desenvolvendo cultivos e criações de animais, bem como privilegiando as seguintes boas práticas de manejo: cobertura morta, adubação orgânica e cultivo misto (Tabela 4). Esses fatores podem estar relacionados à implementação de projetos de agricultura de base agroecológica, em parceria com a UFRPE, no assentamento e à orientação do MST para adotar a Agroecologia como paradigma para a produção agropecuária em assentamentos rurais (DE' CARLI, 2013).

Em termos ambientais, há maior cuidado com o destino do lixo domiciliar. Os resíduos orgânicos têm sido utilizados para a compostagem e o uso dos rios está mais disciplinado, com a preservação das margens e o reflorestamento de setores do assentamento.

Os resultados também mostram que os indicadores controle de pragas e doenças dos cultivos $(0,395)$, usos da mata nativa $(0,463)$ e usos das nascentes $(0,510)$ são os menos expressivos na composição deste sub-índice, embora seus valores oscilem em torno da média. Observou-se que existem ações de conscientização entre os assentados quanto aos efeitos danosos dos agrotóxicos à saúde das pessoas e do agroecossistema, inclusive com capacitações para preparação e uso de produtos alternativos, bem como de produtos microbianos para o controle de pragas e doenças (MATTOS et al., 2017b). À época do estudo os assentados votaram em assembleia à proscrição do uso de agrotóxicos no assentamento, denotando uma crescente compreensão sobre as implicações do uso de agrotóxicos nos cultivos e na saúde (GAMARRA-ROJAS; MATTOS, 2013). Contudo, como o uso de pesticidas sintéticos está fortemente arraigado em todos os setores da agricultura brasileira, seria ingênuo esperar uma ruptura abrupta com essa prática. Quiçá a maior mudança neste sentido ocorra em médio prazo, como consequência do estímulo à diversificação dos cultivos e do conjunto de práticas agroecológicas em curso, que poderão proporcionar um ambiente mais equilibrado aos agroecossistemas $e$, consequentemente, menor incidência de pragas $e$ doenças.

A mata nativa, que foi muito utilizada na época em que os assentados construíram seus barracos provisórios, hoje sofre menor pressão. Contudo, ainda é limitada a compreensão da relação entre a mata originária e os serviços ecossistêmicos usualmente atribuídos à manutenção da diversidade biológica nativa, tais como o controle do microclima local e a regulação dos processos hidrológicos e da abundância de organismos indesejáveis (ALTIERI, 2002). Adicionalmente, as dificuldades financeiras dos assentados ensejam a continuidade da utilização dos recursos madeireiros e energéticos da mata nativa como fonte de renda.

As numerosas nascentes do assentamento em sua maioria já vinham sofrendo impacto desde a época do Engenho São João. O quadro tem sido pouco 
alterado e decorre do desmatamento, da subsequente invasão oportunista pelo capim braquiária e do pisoteio pelas criações no pasto.

O processo de mudança de percepção ambiental e consequente ação em prol da sustentabilidade poderia ser facilitado por um plano que expressasse a visão de futuro dos assentados e que se constituísse em instrumento de gestão e de negociação com terceiros. No âmbito das políticas públicas da reforma agrária brasileira o Plano de Desenvolvimento do Assentamento (PDA) é o instrumento básico para formulação de projetos técnicos e das atividades a serem planejadas e executadas, constituindo-se numa peça fundamental de monitoramento e avaliação dessas ações (MDA, 2008). Entretanto, à época do estudo, apesar de uma tentativa frustrada de construção do PDA de Chico Mendes III em 2009, os assentados não dispunham desse instrumento nem de outro Plano coletivamente pactuado (GAMARRA-ROJAS; MATTOS, 2013). É possível que a inexistência de PDA no assentamento seja uma consequência da elevada expectativa, em termos de complexidade e extensão, do modelo de PDA proposto pelo órgão responsável. Esses fatores de insustentabilidade ambiental em Chico Mendes III alertam para o risco do PDA, como instrumento de política pública, vir mais a privilegiar seu caráter normativo e burocrático do que sua utilidade para os próprios assentados.

\subsection{AUTOGESTÃO EM CHICO MENDES III}

Na formação do Índice de Autogestão (IA) os indicadores participação em organizações na atualidade (24\%) e proveniência das sementes de cultivos de ciclo curto $(20 \%)$ tiveram o maior peso. A maioria dos agricultores assentados produz elevada proporção das sementes utilizadas para os cultivos de ciclo curto e está engajada em algum tipo de organização social, ou seja, todos são membros da associação do assentamento e muitos são militantes do MST (Tabela 4).

O estudo sobre a dinâmica organizativa em Chico Mendes III realizado por Gamarra-Rojas e Mattos (2013) no período de transição das famílias de acampadas para assentadas, apontou sinais de mudanças gradativas nas formas de organização interna e na relação com agentes externos. As ações coletivas dos "núcleos de famílias" foram consideradas herança do MST, uma estratégia própria desse movimento, a qual vem sendo mantida e adaptada pelos assentados devido à sua funcionalidade internamente ao assentamento e por representar um vínculo estratégico com o MST; as atividades da associação do assentamento estavam relacionadas à busca de seus direitos perante o INCRA para consolidação do assentamento e ao acesso a políticas públicas para as novas necessidades que surgem da condição de assentado; a relação dos assentados com o Grupo de Pesquisa em Agroecologia da UFRPE constituía uma instância organizativa emergente com características de comunidade de aprendizagem, a qual se reunia semanalmente em torno da geração e gestão de conhecimento agroecológico.

Atualmente, a Organização de Controle Social (OCS) do Assentamento tem se constituído em mais um espaço de participação para os assentados envolvidos na comercialização direta aos consumidores (MATTOS et al., 2014). Essa diversidade de instâncias organizativas e ações correspondentes ilustram o porquê do indicador participação em organizações na atualidade exercer maior influência no IA do assentamento.

Por sua vez, a autonomia produtiva, representada pela produção e reprodução de material de propagação de cultivos de ciclo curto nos agroecossistemas, tais como as sementes de milho e feijão, as túberas de inhame e as manivas de macaxeira, ilustram outro patrimônio cultural dos camponeses da zona da mata pernambucana, o qual está estreitamente vinculado à diversidade 
produtiva acima destacada na discussão do IP. Nesse sentido, Toledo (1992) e Ploeg (2008), ressaltam que a elevada autossuficiência da unidade de produção camponesa, se caracteriza, dentre outros atributos, pelo consumo de parte substancial da sua produção e pela produção de quase todos os bens de que necessita para se reproduzir. Neste caso, cabe destacar os órgãos de propagação dos cultivos de ciclo curto.

Os indicadores referentes à proveniência de sementes de hortaliças e da alimentação dos animais de pequeno porte foram os que menos contribuíram para a autonomia produtiva (Tabela 4). A dependência sazonal de sementes comerciais de hortaliças é recorrente na agricultura familiar do Nordeste (LIMA; GAMARRAROJAS, 2017) e, aparentemente, há poucas chances de mudança em curto prazo ao nível do agroecossistema familiar ou da comunidade, uma vez que envolve questões biológicas, tecnológicas, econômicas, políticas e normativas, transcendendo aqueles âmbitos. Contudo, há experiências bem-sucedidas no Brasil, que podem servir de inspiração para delinear estratégias e práticas a serem incorporadas desde o início em assentamentos de reforma agrária.

As casas de sementes e as redes de trocas de sementes crioulas, com o elevado grau de desenvolvimento e participação social alcançado em diversas regiões do país, constituem espaços privilegiados para avançar nesses processos de autonomia. Em particular, destaca-se a Rede de Sementes Agroecológicas Bionatur, uma organização de agricultores assentados de reforma agrária e produtores de sementes de diversas espécies, inclusive hortaliças. O principal objetivo dessa rede, vinculada ao MST, é produzir e comercializar sementes agroecológicas que possam ser cultivadas, multiplicadas, conservadas e melhoradas pelos agricultores que as adquirem (SILVA et al., 2014). Uma característica dessa estratégia de autonomia é que todas as variedades são de polinização aberta, o que permite a reprodução, melhoramento e adaptação pelos agricultores às suas condições. Desse modo, diferencia-se de outras formas de produção comercial de sementes que condicionam à aquisição de novas sementes a cada ciclo de cultivo. Considerando-se a experiência da Bionatur (SILVA et al., 2014), seria necessária uma abordagem multidisciplinar e, principalmente, o concurso de parcerias, envolvendo organizações de assessoria, movimentos sociais, grupos organizados de agricultores, a pesquisa em Agroecologia e o Estado no papel de proporcionador de normas e fiscalização.

A alimentação dos animais de pequeno porte no assentamento, principalmente aves, é obtida no próprio lote, exceto na fase inicial e de postura, quando são adquiridas rações balanceadas no mercado. Para mudar esse quadro, têm sido formuladas e produzidas internamente aos sistemas de criação rações à base de feijão guandu, sorgo e macaxeira, em substituição à soja e ao milho, porque a soja encarece o preço da ração e o milho produzido localmente é direcionado prioritariamente para atender à demanda de alimentação da família. A alimentação dos animais de grande porte é feita a pasto dentro do próprio assentamento, exceto no período de seca quando os animais recebem pasto verde picado no cocho, colhido nos arredores do assentamento.

O IA geral é médio $(0,558)$, sugerindo que as famílias agricultoras estão buscando sua autogestão e autonomia produtiva (Tabela 4). Para Gamarra-Rojas e Mattos (2013) a mudança de status de acampado para assentado revela tensões em face de novas oportunidades e pressões, com reflexo nas instâncias organizativas e nas ações individuais dos assentados. É um processo dinâmico, com avanços e retrocessos, tanto ao nível interno quanto nas relações com agentes externos. Supõe uma releitura de estratégias de ação, o fortalecimento de antigas parcerias e a construção de novas alianças. A caminhada das parceiras em Chico Mendes III à 
época revelou a importância da construção de relações de confiança e cooperação, mediadas por ações concretas em busca de objetivos comuns, como forma de favorecer o acesso à informação e a inovação social e produtiva (GAMARRAROJAS; MATTOS, 2013).

Em estudo de sustentabilidade em três assentamentos de reforma agrária do Ceará, Barreto et al. (2005) encontraram um valor médio de capital social, onde o protagonismo organizativo e o espírito democrático são características desses assentamentos rurais. De acordo com Sousa et al. (2015), confiança, cooperação e solidariedade são elementos chave destacados pelos teóricos do capital social, os quais debatem sobre a eficiência das redes de relações sociais e das normas sociais como guias para os indivíduos, que também são reforçadas ou retroalimentadas pelos próprios indivíduos ou de maneira coletiva.

\subsection{SUSTENTABILIDADE EM CHICO MENDES III}

O assentamento apresenta um valor médio de Índice de Sustentabilidade (IS). Analisando a contribuição de cada indicador na formação do IS geral (Tabela $5)$, verifica-se tendência decrescente de influência desde o indicador de estabilidade $(0,631)$, seguido pelo de autogestão $(0,558)$ até o indicador de produtividade $(0,492)$.

Tabela 5. Participação dos indicadores no Índice de Sustentabilidade (IS) em Chico Mendes III, 2010.

\begin{tabular}{lcc}
\hline \multicolumn{1}{c}{ Indicadores } & Valor Absoluto & Contribuição \\
\hline Estabilidade & 0,631 & 38 \\
Autogestão & 0,558 & 33 \\
Produtividade & 0,492 & 29 \\
\hline IS & 0,560 & 100 \\
\hline
\end{tabular}

Fonte: Dados da pesquisa.

A discussão do IS a seguir constitui uma síntese dos elementos-chave da sustentabilidade com base nas análises dos três subíndices realizadas acima. Verifica-se que a estabilidade vem sendo influenciada positivamente por dois fatores associados: i) a agricultura tradicional da Zona da Mata de Pernambuco, baseada em cultivos amiláceos e proteicos de ciclo curto, herdada e praticada pela maioria dos assentados camponeses; e ii) as boas práticas agrícolas, tais como utilização de cobertura morta, de adubo orgânico e a ênfase em policultivos por projetos agroecológicos no assentamento. Desse modo, a estabilidade, à época do estudo, parece ser fortemente determinada pelos cultivos, proporcionando segurança alimentar.

Por sua vez, a autogestão social e a autonomia produtiva são explicadas principalmente pelo concurso de duas estratégias, respectivamente: i) o desenvolvimento de capital social no assentamento que se expressa no protagonismo dos assentados, principalmente das mulheres, na criação e dinamização de diversas instâncias organizativas, as quais resultaram da formação proporcionada pelo MST durante o período de luta pela terra e acampamento; das necessidades e desafios decorrentes da mudança de condição de acampado para assentado; e da emergente comunidade de aprendizagem em torno da Agroecologia do 'roçado de estudos' e ii) a busca de autossuficiência da unidade de produção camponesa, através da reprodução de material de propagação de cultivos tradicionais de ciclo curto em agroecossistemas do assentamento.

O atributo menos expressivo, o de produtividade, poderá adquirir maior importância a partir da definição dos lotes no assentamento o que proporcionaria 
maior segurança às famílias com relação à produção de alimentos e geração de renda agrícola. Nesse sentido, cabe destaque aos cultivos de ciclo longo, principalmente frutíferas, que vêm sendo introduzidas na conformação de sistemas agroflorestais, às áreas de horticultura irrigada e à criação de animais de pequeno e grande porte. O acesso ao crédito rural, uma vez que os requisitos de titulação e distribuição dos lotes estavam sendo definidos em 2011, e a comercialização direta dos produtos do assentamento em feiras agroecológicas, como iniciado também em 2011, poderão contribuir para estimular e dinamizar as unidades produtivas, incrementar a produtividade e aumentar a renda agrícola.

Por outro lado, a produtividade pode também ter sido limitada pela idade relativamente avançada dos assentados e pelo fato de os filhos da maioria dos assentados não participarem dos trabalhos agrícolas no assentamento, o que diminui a sua força de trabalho.

O papel da produtividade em seu sentido amplo é chave no atual estágio de desenvolvimento do assentamento e no futuro imediato. A sua melhoria poderá atuar como ponto de alavancagem dos outros atributos, retroalimentando positivamente 0 sistema como um todo.

\section{CONSIDERAÇÕES FINAIS}

O estudo da sustentabilidade no assentamento Chico Mendes III sugere que a redistribuição da terra aliada a processos organizativos endógenos, protagonizados principalmente pelas mulheres assentadas, juntamente com a revalorização de sistemas de manejo camponesas e a inovação por meio da Agroecologia constituem elementos de um processo de transição agroecológica e recampesinização na reforma agrária.

Como evidenciado nos resultados da pesquisa a transição agroecológica está em curso concomitantemente com a estruturação e consolidação do próprio assentamento. Foram identificados elementos chave de sustentabilidade, como na estabilidade e autogestão, e de insustentabilidade, relacionados à produtividade. Contudo, sendo um estudo realizado há oito anos, a transição agroecológica um processo dinâmico e o assentamento sendo sujeito a muitas forças externas, é preciso cautela. Assim, o estudo proporciona uma linha de base que poderá ser utilizada como referência em futuras avaliações comparativas longitudinais em Chico Mendes III. A realização do presente artigo tem estimulado membros da equipe de pesquisa-ação a dar continuidade aos estudos de sustentabilidade no assentamento, aproveitando para isso as relações de confiança existentes e a relativa simplicidade da metodologia de indicadores ora utilizada. Considerando-se os fatores de insustentabilidade acima apontados, futuros estudos deveriam dar particular atenção à sucessão em assentamentos de reforma agrária.

Embora a recampesinização não fosse o foco da pesquisa, o próprio objeto de estudo - assentamento rural - e a discussão dos resultados conduzem inevitavelmente ao tema. Assim a recampesinização dos assentados pode ser percebida ao menos nos seguintes aspectos: na mobilização para a criação do assentamento numa perspectiva de resistência, que culminou com o acesso à terra, superando a desterritorialização a que estiveram submetidos; na busca de autossuficiência da unidade de produção, apesar de limitações decorrentes da idade media avançada e do baixo nível de escolaridade; na valorização dos conhecimentos tradicionais e recursos locais, face às dificuldades de acesso ao crédito e; no estabelecimento de alianças em processos de aprendizagem e de desenvolvimento socioambiental, que decorre da mobilização de competências diversas em interação com diferentes atores sociais. 
A análise crítica foi favorecida pela pesquisa-ação, empregada como estratégia pedagógica pela equipe de extensão agroecológica da UFRPE no assentamento. Sem essa vivência da equipe os índices continuariam a ser úteis, acusando diferenças e direcionando a atenção para fatores críticos, mas a discussão ficaria descontextualizada, limitando a teorização. Estes resultados reforçam a relevância das abordagens dialógica e transdisciplinar em processos de transição agroecológica, seja na Assessoria Técnica, Social e Ambiental à Reforma Agrária (ATES) ou na Assistência Técnica e Extensão Rural (ATER) de maneira mais ampla, como estratégias de politica pública para o desenvolvimento rural sustentável.

\section{REFERÊNCIAS}

ALTIERI, M.A. O agroecossistema: fatores determinantes, recursos, processos e sustentabilidade. In: ALTIERI, M.A. (Ed.) Agroecologia: bases científicas para uma agricultura sustentável. Guaíba, RS: Agropecuária, 2002. p.85-124.

ALTIERI, M.A.; YURJEVIC, A. La agroecología y el desarrollo rural sostenible en América Latina. Revista Agroecología y Desarrollo, v.1, n.1, 1991. Disponível em: https://repositorio.cepal.org/bitstream/handle/11362/33761/S9200648_es.pdf?seque nce=1\&isAllowed=y. Acesso em: 17 abr. 2019.

ASTIER, M. Medición de la sustentabilidad en sistemas agroecológicos. In: CONGRESO DE LA SOCIEDAD ESPAÑOLA DE AGRICULTURA ECOLÓGICA, 2006, Zaragoza, España. Anais... Zaragoza: SEAE, 2006. 6p.

BACHEV, H.; TERZIEV, D. A study on institutional, market and natural environment impact on agrarian sustainability in Bulgaria, Journal of Environmental Management and Tourism, v.3, n.27, p.452-478, 2018.

BARRETO, R.C.S.; KHAN, A.S.; LIMA, P.V.P.S. Sustentabilidade dos assentamentos no município de Caucaia-CE. Revista Brasileira de Economia e Sociologia Rural. Brasília, v.43, n.2, p.225-247, 2005.

BELLEN, H.M. V. Indicadores de sustentabilidade: uma análise comparativa. Rio de Janeiro: Editora FGV, 2005. 256p.

CALVO-GONZÁLEZ, E. Construindo a comunidade: um assentamento do MST no Nordeste. In: CARTER, M. (Org.) Combatendo a desigualdade social: o MST e a reforma agrária no Brasil. São Paulo: Editora UNESP, 2010. p.353-372.

CASTOLDI, N.; BECHINI, L. Integrated sustainability assessment of cropping systems with agro-ecological and economic indicators in northern Italy. European Journal of Agronomy, v.32, n.1, p.59-72, 2010.

CONWAY, G.R. Agroecosystem analysis for research and development. Bangkok: Winrock International, 1986. 112p.

CONWAY, G.R. The properties of Agroecosystems. Agricultural Systems, n.24, p.95-117, 1987. 
DE' CARLI, C. O discurso político da agroecologia no MST: O caso do Assentamento 17 de Abril em Eldorado dos Carajás, Pará. Revista Crítica de Ciências Sociais, n.100, p.105-130, 2013.

GAMARRA-ROJAS, G.; MATTOS, J.L.S. Fácies de mudança em assentamento de reforma agrária de Pernambuco. In: CONGRESSO DA SOCIEDADE BRASILEIRA DE ECONOMIA, ADMINISTRAÇÃO E SOCIOLOGIA RURAL, 51, 2013, Belém. Anais... Belém, PA: SOBER, 2013. 11p. Disponível em: http://icongresso.itarget.com.br/useradm/anais/?clt=ser.3. Acesso em: 30 nov. 2013.

GAMARRA-ROJAS, G.; SILVA, N.C.G.; VIDAL, M.S.C. Contexto, (agri)cultura e interação no agroecossistema familiar do caju no semiárido brasileiro. Cadernos de Ciência \& Tecnologia, v.34, n.3, p.59-82, 2017.

GBETIBOUO, G.A.; RINGLER, C.; HASSAN, R. Vulnerability of the South African farming sector to climate change and variability: an indicator approach. Natural Resources Forum, v.34, n.3, p.175-187, 2010.

GLIESSMAN, S. Agroecologia. Procesos ecológicos en agricultura sostenible. Turrialba, C.R.: Catie, 2002. p.319-329.

GÓMEZ-LIMÓN, J.A.; SANCHEZ-FERNANDEZ, G. Empirical evaluation of agricultural sustainability using composite indicators. Ecological Economics, v.69, n.5, p.1062-1075, 2010.

HANNAA, S.H.S.; OSBORNE-LEEB, I.W.; CESARETTI, G.P.; MISSO, R.; KHALIL, M.T. Ecological agro-ecosystem sustainable development in relationship to other sectors in the economic system, and human ecological footprint and imprint. Agriculture and Agricultural Science Procedia, v.8, p.17-30. 2016.

HOLLING, C.S. Understanding the complexity of economic, ecological, and social systems. Ecosystems, v.4, n.5, p.390-405, 2001.

KOOHAFKAN, P.; ALTIERI, M.A.; GIMENEZ, E.H. Green agriculture: foundations for biodiverse, resilient and productive agricultural systems. Int. J. Agric. Sustainability, v.10, n.1, p.1-13, 2012.

LEITE, S.; HEREDIA, B.; MEDEIROS, L. et al. (Coord.). Impactos dos assentamentos: um estudo sobre o meio rural brasileiro. Brasília: Instituto Interamericano de Cooperação para Agricultura - IICA, Núcleo de Estudos Agrários e Desenvolvimento Rural - NEAD. São Paulo: Unesp, 2004. 392p. (Estudos NEAD, 6)

LIMA, R.V.; GAMARRA-ROJAS, G. Camponeses e a mandalla no semiárido brasileiro: reflexões sobre sustentabilidade com base em um estudo de caso com abordagem agroecossistêmica. Cadernos de Ciência \& Tecnologia, v.34, n.2, p.161-195, 2017.

MARTEN, G.G. Productivity, stability, sustainability, equitability and autonomy as properties for agroecosystem assessment. Agricultural Systems, n.26, p.291-316, 1988. 
MASERA, O.; ASTIER, M.; LÓPEZ-RIDAURA, S. Sustentabilidad y manejo de recursos naturales. El marco de evaluación MESMIS. México: Grupo Interdisciplinario de Tecnología Rural Apropiada; Instituto de Ecología; MundiPrensa, 2000. 109p.

MATTOS, J.L.S.; GUZMÁN-CASADO, G.I.; CAPORAL, F.R.; SILVA, L.M.S.; SANTOS FILHO, D.A.; SILVA, J.F.; FONSECA, F.D. A transição agroecológica no assentamento Chico Mendes-PE: uma avaliação de agroecossistemas sustentáveis. In: JORNADA DE ESTUDOS EM ASSENTAMENTOS RURAIS, 7, 2017, Campinas. Anais... Campinas: Unicamp. 2017a. 16p.

MATTOS, J.L.S.; GUZMÁN-CASADO, G.I.; LIMA, J.R.T.; GAMARRA-ROJAS, G.; SILVA, J.N. La recampesinización del mundo rural brasileño: el caso de las mujeres del Asentamiento Chico Mendes III. In: CONGRESO DE LA SOCIEDAD ESPAÑOLA DE AGRICULTURA ECOLÓGICA, 21, 2014, Vitoria-Gasteiz, Álava, España. Actas... Vitoria-Gasteiz, Álava: SEAE, 2014. p.225-248.

MATTOS, J.L.S.; LIMA, J.R.; SILVA, J.N.T.; GAMARRA-ROJAS, G.; CAPORAL, F.R.; FONSECA, F.D. A formação em extensão rural agroecológica consubstanciada na metodologia camponês a camponês. In: JORNADA DE ESTUDOS EM ASSENTAMENTOS RURAIS, 7, 2017, Campinas. Anais... Campinas: Unicamp. 2017b. 17p.

MINISTÉRIO DO DESENVOLVIMENTO AGRÁRIO - MDA; INSTITUTO NACIONAL DE COLONIZAÇÃO E REFORMA AGRÁRIA - INCRA. Manual Operacional ATES. Brasília, DF: MDA, INCRA, 2008. Disponível em: http://pfdc.pgr.mpf.mp.br/atuacaoe-conteudos-de-apoio/publicacoes/reforma-agraria/questao-

fundiaria/manual_ates_2008_revisado.pdf. Acesso em: 27 ago. 2017.

NUNES DA SILVA, J.; MATTOS, J.L.S.; DINIZ, P.C.O.; VASCONCELOS, G.O.S. Transição agroecológica em assentamentos rurais: o processo inicial no assentamento Chico Mendes III/PE-Brasil. In: CONGRESSO DA SOCIEDAD LATINOAMERICANA DE AGROECOLOGIA E ASSOCIAÇÃO BRASILEIRA DE AGROECOLOGIA, 2009, Curitiba, Paraná. Resumos do VI CBA e II CLAA. Rev. Bras. De Agroecologia. v.4, n.2, p.3022-3025, 2009.

OELBERMANN M. (Ed.) Sustainable agroecosystems in climate change mitigation. Wageningen Academic Publishers, 2014. 272p.

PIRES, M.O. Desenvolvimento e sustentabilidade: um estudo sobre o Programa de Cooperação Nipo-Brasileira para o Desenvolvimento dos Cerrados (PRODECER). 1996. 200f. Dissertação (Mestrado em Sociologia) - Departamento de Sociologia. Universidade de Brasília.

PLOEG, J.D.V D. Camponeses e impérios alimentares: lutas por autonomia e sustentabilidade na era da globalização. Porto Alegre, RS: Editora da UFRGS, 2008. $376 \mathrm{p}$.

PRETTY, J. et al. The top 100 questions of importance to the future of global agriculture. International Journal of Agricultural Sustainability, v.8, n.4, p.219236, 2010. Disponível em: www.earthscan.co.uk/journals/ijas. Acesso em: 17 abr. 2019. 
RAMÍREZ-CARRILLO, E.; LÓPEZ-CORONA, O.; TOLEDO-ROY, J.C.; LOVETT, J.C.; LEÓN-GONZÁLEZ, F.; OSORIO-OLVERA, L.; EQUIHUA, J.; ROBREDO, E.; FRANK, A.; DIRZO, R.; PÉREZ-CIRERA, V. Assessing sustainability in North America's ecosystems using criticality and information theory. PLoS ONE, v.13, n.7, 2018.

RÖLING, N.G.; WAGEMAKERS, M.A.E. A new practice: facilitating sustainable agriculture. In: RÖLING, N.G.; WAGEMAKERS, M.A.E. (Ed.) Facilitating sustainable agriculture. Participatory learning and adaptive management in times of environmental uncertainty. Cambridge University Press, 1998. p.3-22.

SILVA, P.M.; GAIARDO, A.; INHAIA, A.; MORALES, M.G.; ANTUNES, I.F. Rede de Sementes Agroecológicas Bionatur: uma trajetória de luta e superação. Agriculturas, v.11, n.1, p.33-37, 2014.

SOUSA, G.M.R.; GAMARRA-ROJAS, G.; NUNES, E.M.; REIS, J.N.P.; BENTO, J.A.N. Análise do capital social da agricultura no município de Pentecoste (CE). Revista de Estudos Sociais, v.17, n.34, p.83-99, 2015.

SOUSA, M.C. de; LIMA, P.V.P.S.; KHAN, A.S.; ROCHA, L.A. Confluência do capital social, empoderamento e governança ambiental na sadia qualidade de vida em comunidades rurais no Ceará. Rev. Econ. Sociol. Rural, v.55, n.4, p.711-732, 2017. Disponível em: http://dx.doi.org/10.1590/1234-56781806-94790550406. Acesso em: 30 jul. 2019.

SRINIVASA RAO, C.; KAREEMULLA, K; KRISHNAN, P.; MURTHY, G.R.K.; RAMESH, P.; ANANTHAN, P.S.; JOSHI, P.K. Agro-ecosystem based sustainability indicators for climate resilient agriculture in India: a conceptual framework. Ecological Indicators, v.105, p.621-633, 2019.

TOLEDO, V.M. La racionalidad ecológica de la producción campesina. Revista Agroecología y Desarrollo, Número Especial 5/6 Diciembre, 1992. Disponível em: http://www.clades.cl/revistas/5/rev5art3.htm. Acesso em: 23 nov. 2016.

TONMOY, F.N.; EL-ZEIN, A. Assessment of vulnerability to climate change using indicators: methodological challenges. In: DINCER, I.; COLPAN, C.O. (Ed.) Causes, impacts, and solutions to global warming. New York, NY: Springer, 2013. p.143156.

WOODHILL, J.; RÖLING, N.G. The second wing of the eagle: the human dimension in learning our way to more sustainable futures. In: RÖLING, N.G.; WAGEMAKERS, M.A.E. (Ed.) Facilitating sustainable agriculture. Participatory learning and adaptive management in times of environmental uncertainty. Cambridge University Press, 1998. p.46-71.

YIN, R.K. Estudo de caso: planejamento e métodos. 3.ed. Porto Alegre: Bookman, 2005. 212p. 